\title{
Different solutions used for submucosal injection influenced early healing of gastric endoscopic mucosal resection in a preclinical study in experimental pigs
}

\author{
Jan Bureš • Marcela Kopáčová · Jaroslav Květina · Jan Österreicher · \\ Zuzana Šinkorová $\cdot$ Zbyněk Svoboda $\cdot$ Ilja Tachecí $\cdot$ Stanislav Filip $\cdot$ \\ Stanislav Špelda $\cdot$ Martin Kuneš $\cdot$ Stanislav Rejchrt
}

Received: 31 May 2008/ Accepted: 6 October 2008/Published online: 5 December 2008

(c) The Author(s) 2008. This article is published with open access at Springerlink.com

\begin{abstract}
Background We hypothesised that different solutions for submucosal injection may influence early healing of endoscopic mucosal resection (EMR). The aim of this study was to evaluate histological and immunological changes after EMR in experimental pigs.

Materials and methods Two parallel EMRs on the anterior and posterior wall of the gastric body were performed by means of the cap technique in 21 female pigs. A glycerolbased solution (anterior EMR) and hydroxypropyl methylcellulose solution (posterior EMR) were applied for submucosal injection. The animals were sacrificed 7 days
\end{abstract}

This work was presented in part at the 15th United European Gastroenterology Week, October 2007, Paris, France (histochemical study) and at the Digestive Disease Week, May 2008, San Diego, California, USA (immunological study).

J. Bureš $(\bowtie) \cdot$ M. Kopáčová · I. Tachecí · S. Rejchrt Second Department of Internal Medicine, Charles University in Praha, Faculty of Medicine at Hradec Králové, University Teaching Hospital, Sokolská 581, 50005 Hradec Králové, Czech Republic

e-mail: bures@lfhk.cuni.cz

J. Květina $\cdot$ Z. Svoboda $\cdot$ M. Kuneš

Institute of Experimental Biopharmaceutics, Joint Research Center of Czech Academy of Sciences and PRO.MED.CS Praha a.s., Hradec Králové, Czech Republic

J. Österreicher $\cdot$ Z. Šinkorová $\cdot$ S. Špelda

Department of Radiobiology, Faculty of Military Health

Sciences, University of Defense, Hradec Králové,

Czech Republic

S. Filip

Department of Oncology and Radiotherapy, Charles University in Praha, Faculty of Medicine at Hradec Králové, University

Teaching Hospital, Hradec Králové, Czech Republic later, and tissue sections of all EMRs were stained using combined trichrome. Computer image analysis was used for objective evaluation of elastic and collagen fibres content. Two-colour indirect immunophenotyping of blood and gastric samples were performed using mouse anti-pig monoclonal antibodies.

Results The values of collagen fibre content 7 days after EMR were significantly higher in lesions after the use of solution A in comparison with solution B $(2.10 \pm 0.25 \%$ versus $1.57 \pm 0.25 \%, p=0.009)$. Concordant results were found in elastic fibres $(3.23 \pm 0.49 \%$ versus $2.93 \pm$ $0.61 \%, p=0.018)$. No systemic changes in major leukocyte subpopulations were found. In gastric tissue, lymphocyte subsets exhibited only minor changes. CD4 ${ }^{+}$ T-lymphocytes were increased in the healing tissue after EMR using solution A $(17.08 \pm 9.24 \%$ versus $9.76 \pm$ $7.97 \%, p=0.011)$. Significant increase of $\mathrm{SWC}^{+}$leukocytes was observed after EMR using solution B $(47.70 \pm 25.41 \%$ versus $18.70 \pm 12.16 \%, p=0.001)$.

Conclusions The use of glycerol-based solution for submucosal injection was associated with more pronounced histological signs of early healing of EMRs compared with hydroxypropyl methylcellulose.

Keywords Submucosal injection - Healing · Gastric endoscopic mucosal resection - Experimental pigs

Endoscopic mucosal resection (EMR) has been widely used as a therapeutic method for resection of nonpolypoid lesions of the gastrointestinal tract, mostly of early cancer [1]. It was originally developed in Japan for the purpose of obtaining a larger biopsy specimen (strip-off biopsy) [2] and later revised to its current form [3, 4]. Most EMR techniques 
require use of submucosal injection to separate the lesion from the muscularis propria and thus reduce thermal injury and the risk of perforation and hemorrhage [1, 5-7].

In clinical endoscopy, numerous submucosal injection solutions have been proposed for EMR (such as saline solution with or without epinephrine, glucose, glycerol, hyaluronic acid or autologous blood) [1, 8-18]. However, no definitive proof of the superiority of any solution based on comparative studies has been provided and thus no conclusive recommendation for daily routine practice is available.

Preclinical studies in an experimental setting enable more detailed and precise evaluation as a paired arrangement of different solutions in a single animal is possible (to reduce interindividual variability), particular appraisal criteria can be set in advance and followed (i.e. histology, immunology, final outcome etc.) and defined variables can be exactly determined (i.e. different viscosity, electrical characteristics, injected volume etc.). In addition to this, the small adult pig can be used in experiments as an omnivorous representative due to its very similar gastrointestinal functions to man [19].

Previous studies of submucosal injection solutions for EMR have mostly evaluated ability to create a submucosal fluid cushion and its duration. Most authors think that sufficient duration of lesion lifting is more important for successful results of EMR than the types of solutions used themselves. However, only a limited amount of attention has been paid to the potential of injury to the muscularis propria. Possible tissue damage of the muscularis propria may result in impaired healing or even delayed complications (bleeding, perforation, stricture or stenosis) [20].

The overall objective of the present study was to evaluate the early histological and immunological markers of mucosal healing after gastric EMR in experimental pigs. We hypothesised that different composition of solutions of different viscosity used for submucosal injection could influence the early healing of EMR.

\section{Materials and methods}

Animals

Twenty-one mature female pigs (Sus scrofa f. domestica), hybrids of Czech White and Landrace breeds, weighing $34.1 \pm 3.4 \mathrm{~kg}$ (4-5 months old), entered the study. They were kept in air-conditioned rooms $\left(22 \pm 2{ }^{\circ} \mathrm{C}\right.$ and $50 \pm 10 \%$ relative humidity, with lights from 07:00 to 19:00 hours), fed twice a day (standard assorted food A1) and allowed access to water ad libitum. Handling of experimental animals was performed under the supervision of the Institutional Board of Animal Care of the Institute of
Experimental Biopharmaceutics, Academy of Sciences of the Czech Republic.

Drugs

All endoscopies were carried out under general anaesthesia. Intramuscular injection of ketamine $(20 \mathrm{mg} / \mathrm{kg}$; Narkamon, Spofa, Praha, Czech Republic), azaperone $(2 \mathrm{mg} / \mathrm{kg}$; Stresnil, Janssen-Pharmaceutica, Beerse, Belgium) and atropine $(0.05 \mathrm{mg} / \mathrm{kg}$; Atropin, Biotika, Slovenská Ľupča, Slovakia) was used as an induction, continued by infusion of $1 \%$ thiopental (up to $25 \mathrm{mg} / \mathrm{kg}$; Thiopental, Valeant Czech Pharma, Praha, Czech Republic) administrated to the lateral auricle vein.

Omeprazole (Zentiva, Praha, Czech Republic) was administrated as an i.v. bolus $(40 \mathrm{mg})$ at the end of endoscopy to decrease the gastric production of hydrochloric acid and thus facilitate early healing of the base after EMRs.

For the pharmacological euthanasia i.v. administration of embutramide, mebezonium iodide and tetracaine hydrochloride (T61, Intervet International BV, Boxmeer, the Netherlands; dose of $2 \mathrm{~mL} / \mathrm{kg}$ ) was used.

\section{Solutions for submucosal injection}

Two different solutions were used for submucosal injection in each animal. Solution A contained 10\% glycerol, 10\% glucose and $0.1 \%$ Patent Blue V (Guerbet, Roissy, France); its viscosity was $1.69 \mathrm{mPa} . \mathrm{s}$ at $20^{\circ} \mathrm{C}$. Solution B contained $0.85 \%$ hydroxypropyl methylcellulose in Ringer solution (Ivax Pharmaceuticals, Opava, Czech Republic), with a viscosity of $20.0 \mathrm{mPa}$.s at $20^{\circ} \mathrm{C}$.

\section{Endoscopy}

All experiments were performed in the morning after overnight fasting in an aseptic operating room. Endoscopy procedures were performed using videogastroscopes GIFQ130 (Olympus Optical Co, Tokyo, Japan) dedicated for animal use only. Two parallel standard EMRs on the anterior and posterior wall of the gastric body were performed by means of the cap technique in one session in all animals. Transparent soft caps with a diameter of $17.2 \mathrm{~mm}$ (MH 466, Olympus Optical Co, Tokyo, Japan) and EMR polypectomy snares (SD-221U-25, Olympus Optical Co, Tokyo, Japan) were used for EMRs. Solution A for the anterior EMRs and solution B for the posterior EMRs were applied; $10 \mathrm{~mL}$ of each solution was used for each submucosal injection. A 30-W seal cut (B Braun Aesculap, Melsungen, Germany) was used for all EMRs. Mucosa specimens were retrieved for subsequent histological and immunological investigation. Submucosal tattooing using a 
suspension of highly purified carbon particles (Spot, GI Supply, Camp Hill, USA) was performed close (about $2 \mathrm{~cm}$ ) to EMR with solution A on the anterior gastric wall. Each couple of EMRs in a single animal was performed by the same endoscopist (J.B. or M.K.). All endoscopies were video-recorded on digital versatile disk (DVD).

Animals were allowed food and water immediately after their recovery from general anaesthesia. Seven days later, the pigs were sacrificed by means of pharmacological euthanasia. Immediate autopsy was performed. Macrophotographs of the stomach with healing EMRs were taken and afterwards specimens of the gastric body were obtained at autopsy for subsequent analysis.

A 7-day interval was chosen based on results of a pilot testing EMRs performed previously in four animals with subsequent histological analysis of healing of EMRs on days $3,5,7$, and 11 .

\section{Histology}

The parts of gastric mucosa obtained by means of EMR (two samples from each animal) and specimens of gastric body at the area of previous EMR 7 days later (two samples from each animal) were carefully fixed with $10 \%$ neutral buffered formalin. Samples were subsequently embedded into paraffin, 1- $\mu$ m-thick tissue sections were cut and Gram staining for bacteria as well as combined trichrome (green trichrome with Orange Q) staining were provided.

\section{Image analysis}

Stained samples were evaluated by using BX-51 microscope (Olympus Optical Co, Tokyo, Japan) and ImagePro 5.1 computer image analysis (Media Cybernetics, Bethesda, USA). Six microscopic fields with a size of $20,000 \mu \mathrm{m}^{2}$ at $600 \times$ original magnification were randomly selected from each sample for evaluation of elastic and collagen fibres content. The positive RGB structures were detected in the range: red, green, and blue for elastic fibres, where 0 is black and 255 is white as well as inverted RGB in the range: red, green, and blue detecting collagen fibres, where 0 is white and 255 is black. The percentage positivity of the viewing fields was subsequently measured. Percentage positivity means the percentage of positive objects.

Immunophenotyping of cells

\section{Blood samples}

Heparinised peripheral blood was obtained from vena cava cranialis just before EMR and 7 days later before pharmacological euthanasia in all experimental animals. Erythrocytes were removed using EasyLyse (Dako,
Glostrup, Denmark) lysing solution according to the manufacturer's instructions. Remaining leukocytes were washed twice by means of centrifuging and resuspending the pellet in an ice-cold washing and staining buffer (WSB, phosphate-buffered saline containing $0.1 \%$ sodium azide and $0.02 \%$ gelatine from cold water fish skin, all reagents from Sigma-Aldrich, St. Louis, USA). Cells were counted and their density was set to $5 \times 10^{6}$ per $\mathrm{mL}$.

\section{Gastric samples}

Gastric mucosa was obtained by means of EMR using either solution A or B. The samples from the healing lesions were excised at autopsy. Mucus was removed from the tissue by means of washing with phosphate-buffered saline and the cells from the superficial part of the tissue were released by gentle scraping using a scalpel; tissue aggregates were homogenised by pipetting. The suspension was then filtered through a fine nylon mesh and washed twice in ice-cold WSB, cells were counted and their density was set to $5 \times 10^{6}$ per $\mathrm{mL}$. All samples were kept on ice until immunostaining.

\section{Cell staining}

Two-colour indirect immunophenotyping was performed as described elsewhere [21]. Briefly, $100 \mu \mathrm{L}$ of the cell suspension $\left(5 \times 10^{6}\right.$ cells $)$ was incubated for $30 \mathrm{~min}$ with a pair of optimally titrated mouse anti-pig monoclonal antibodies of different (sub)isotypes in 96-well microtitration plates, washed twice in WSB and Fc receptors on the cell surface were subsequently blocked by incubating the cells in WSB containing $10 \%$ heat inactivated nonimmune normal goat serum. After another centrifugation step, the binding of primary immunoreagents was visualised by resuspending the cells in WSB containing an appropriate cocktail of fluorescein isothiocyanate and phycoerythrinconjugated goat anti-mouse polyclonal antisera specific for mouse Ig (sub)isotypes (Southern Biotech, Birmingham, USA). After $20 \mathrm{~min}$ of incubation the cells were washed twice in WSB. The panel of the following mouse anti-pig monoclonal antibodies was used: anti-CD45 (K252.1E4, IgG1), anti-CD2 (MSA4, IgG2a), anti-CD3 $\varepsilon$ (PPT3, IgG1), anti-CD4 (10.2H2, IgG2b), anti-CD8 (76-2-11, IgG2a), anti-TCR $\gamma \delta$ (PPT16, IgG2b), anti-SWC3a (74-22-15, IgG2b) and anti-IgM (Lig4, IgG1).

\section{Flow cytometry}

The samples were acquired on a CyAn ADP analyser (Dako, Glostrup, Denmark) and 30,000-500,000 events were collected in each sample depending on leukocyte proportions. Damaged and dead cells were excluded from 
analysis using propidium iodide $(10 \mu \mathrm{L} / \mathrm{mL})$ fluorescence. Data analysis was performed using Summit 4.3 software (Dako, Glostrup, Denmark).

\section{Statistical analysis}

Data were statistically analysed with paired $t$-test and Mann-Whitney rank-sum test. The second-type error $\beta$ was calculated when appropriate. Statistical software used for these analyses was SigmaStat version 3.1 (Jandel Corp, Erkrath, Germany). A $p$-value of less than 0.05 was accepted as statistically significant.

\section{Ethics}

The study was approved by the Institutional Review Board of Animal Care Committee of the Institute of Experimental Biopharmaceutics, Academy of Sciences of the Czech Republic, Protocol Number 149/2006. Animals were held and treated in accordance with the European Convention for the Protection of Vertebrate Animals Used for Experimental and Other Scientific Purposes [22].

\section{Results}

Histology and image analysis

There was no gross complication of the EMR itself in any animal (Fig. 1). No presence of bacterial infection in any sample (as a complication of EMR) was found in histology.

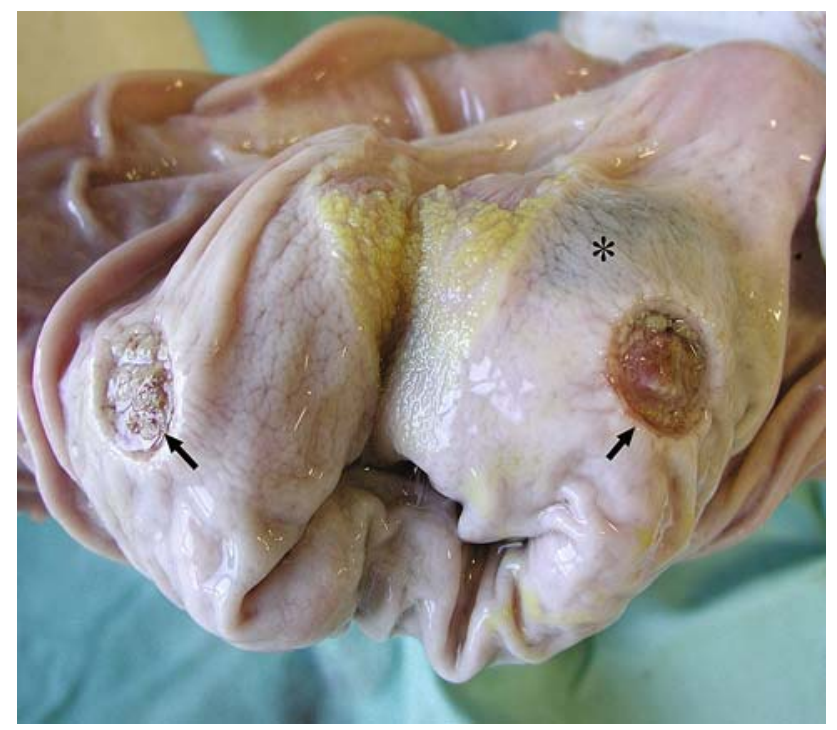

Fig. 1 Representative view of two healing lesions 7 days after EMRs. The posterior wall is on the left and the anterior one on the right. Submucosal tattooing by suspension of highly purified carbon particles is marked by an asterisk
The results of quantitative histological detection of combined trichrome staining of granulous tissue in the healing lesions of the gastric wall after EMRs are shown in Table 1. The values of elastic fibre content 7 days after EMR were significantly higher in lesions after the use of solution A in comparison with after use of solution B (Figs. 2 and 3). The same results were observed during measuring of content of collagen fibres. Lesions after EMR using solution A expressed a higher percentage of collagen fibres than those having used the solution B for submucosal injection before EMRs (Figs. 4 and 5).

Leukocyte population and lymphocyte subsets analysis

No systemic changes in major leukocyte populations, lymphocyte subpopulations and their subsets were found during the experiment. As typical for an outbred population, individual pigs differed in the proportions of major lymphocyte subpopulations and subsets in peripheral blood and the gastric EMR did not cause any significant changes or trends in circulation. Well-defined lymphocyte subsets such as $\mathrm{CD} 4^{+} \mathrm{CD} 8^{+}$double-positive $\mathrm{T}$ cells, $\mathrm{CD} 4^{-} \mathrm{CD} 8^{+}$ and $\mathrm{CD} 4^{+} \mathrm{CD} 8^{-}$cytotoxic and helper/regulatory $\alpha \beta \mathrm{T}$ cells, respectively, $\mathrm{CD}^{-} \mathrm{CD}^{+} \mathrm{NK}$ cells, $\mathrm{TCR} \gamma \delta^{+} \mathrm{T}$ cells

Table 1 Content of collagen and elastic fibres in granulous tissue 7 days after EMR, in percent mean \pm standard error on the mean (SEM)

\begin{tabular}{llll}
\hline Parameter & Solution A & Solution B & Significance \\
\hline Collagen fibres & $2.10 \pm 0.25$ & $1.57 \pm 0.25$ & $p=0.009^{*}$ \\
Elastic fibres & $3.23 \pm 0.49$ & $2.93 \pm 0.61$ & $p=0.018^{*}$ \\
\hline
\end{tabular}

* Mann-Whitney rank-sum test

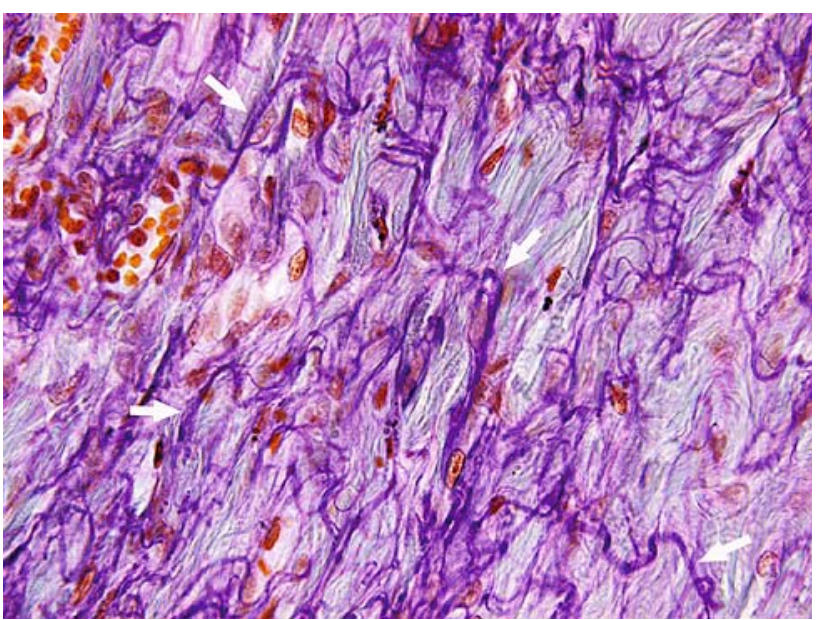

Fig. 2 Detailed view of granulous tissue (magnification $600 \times$ ) 7 days after EMR in the stomach (solution A). Elastic fibres are bright violet (arrows). Combined trichrome (green trichrome with Orange Q) staining 


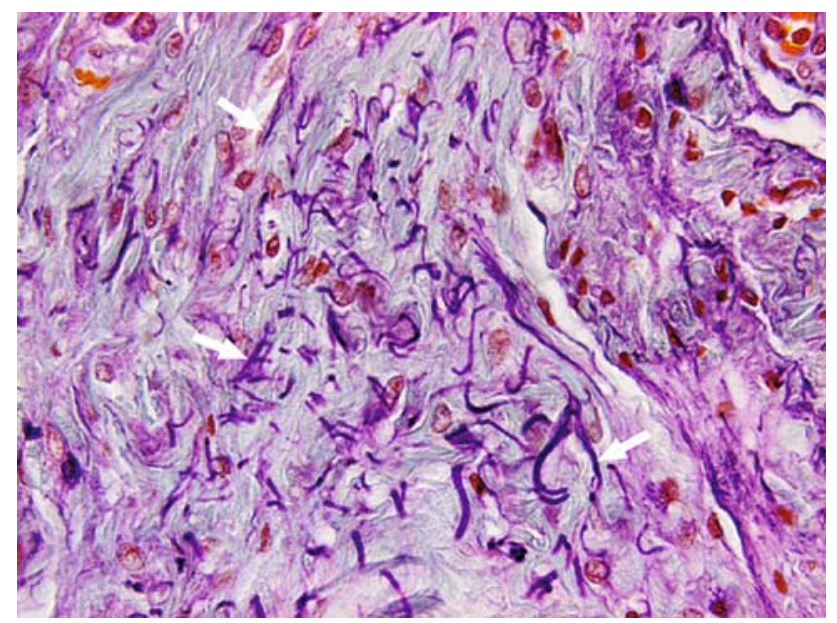

Fig. 3 Detailed view of granulous tissue (magnification $600 \times$ ) 7 days after EMR in the stomach (solution B). Elastic fibres are bright violet (arrows). Combined trichrome (green trichrome with Orange Q) staining

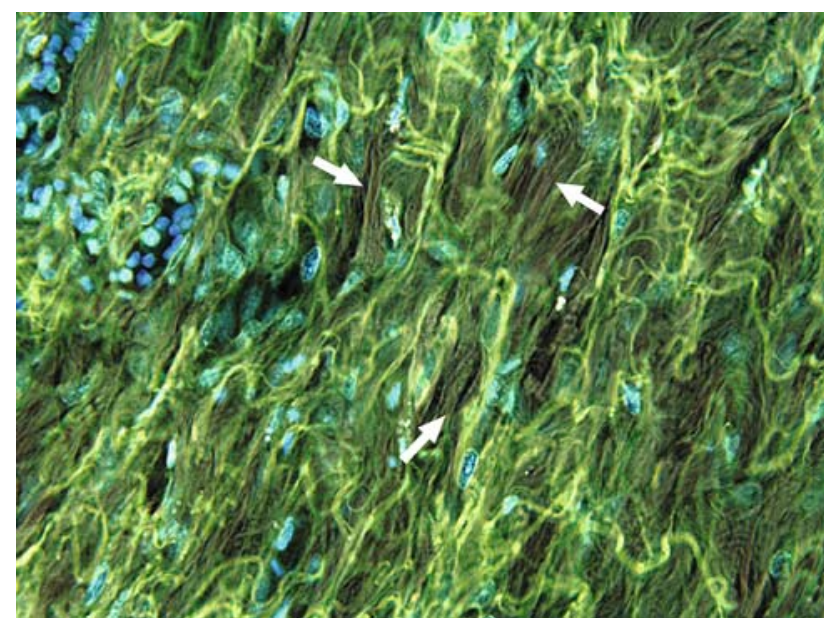

Fig. 4 Inverted image of Fig. 2, demonstrating numerous collagen fibres in dark brown (arrows)

or B cell subsets differing in CD2 expression exhibited only minor changes typical for different collection days in individual pigs (data not shown). Similar to lymphocytes, analysis of myelomonocytic cells in peripheral blood did not reveal any reproducible changes before and 7 days after EMR.

In gastric samples, the $\mathrm{CD}^{+}$single-positive T-cells appeared to increase their relative numbers in the healing wound 7 days after the submucosal injection of solution A $(9.76 \pm 7.97 \%$ versus $17.08 \pm 9.24 \%, p=0.011)$. In tissue samples, a significant increase of the proportion of $\mathrm{SWC}^{+}$ leukocytes was observed on day 7 (compared with day 1) after the submucosal injection of solution B $(18.70 \pm 12.16 \%$ versus $47.70 \pm 25.41 \%, p=0.001)$. Results with solution $\mathrm{A}$ appeared to have a similar trend but the difference between day 1 and 7 was not statistically significant. There was no

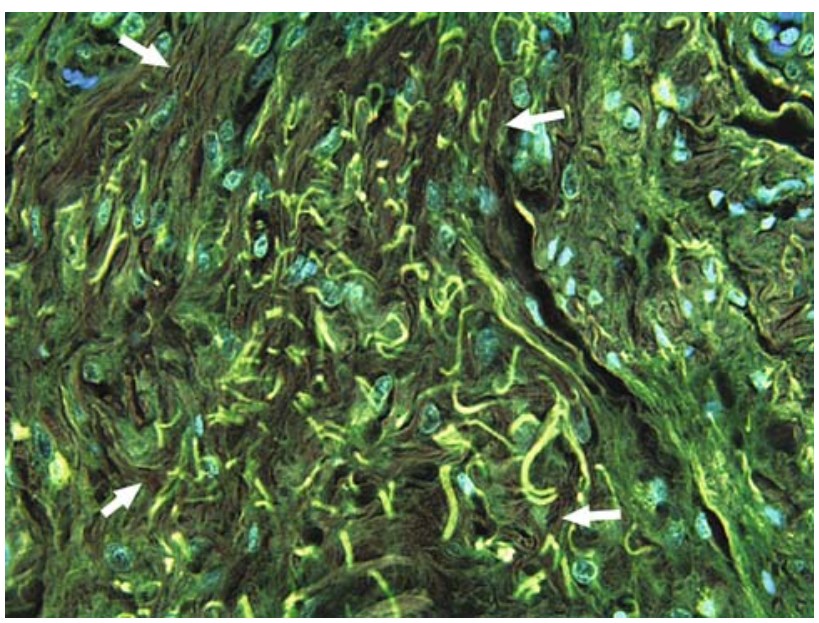

Fig. 5 Inverted image of Fig. 3, demonstrating numerous collagen fibers in dark brown (arrows)

significant difference in the proportion of $\mathrm{SWC}^{+}$leukocytes on day 7 after the use of solutions A or B ( $p=0.129$; power of the performed test 0.198). Scatter characteristics of the myelomonocytic $\left(\mathrm{SWC}^{+}\right)$population that enlarged its size after EMR suggested that such cells were granulocytes (high side scatter values).

\section{Overall healing characteristics}

The results of particular parameters displayed above clearly show that different solutions used for submucosal injection before EMR influenced early signs of healing assessed by histology. The use of the glycerol-based solution was associated with more pronounced histological signs of early healing compared with the solution of hydroxypropyl methylcellulose. There were no significant changes of major leukocyte populations, lymphocyte subpopulations and myelomonocytic cells in peripheral blood as a systemic response 7 days after EMRs. The increased myelomonocytic population in the healing lesion after EMR were granulocytes.

\section{Discussion}

In this study, we compared different solutions used for submucosal injection and evaluated their impact on early mucosal healing after gastric EMR in experimental pigs. The use of the glycerol-based solution was associated with more pronounced histological signs of early healing compared with the solution of hydroxypropyl methylcellulose. Both solutions are highly hydrophilic but they markedly differed in their viscosity. However, the possible beneficial mechanism of glycerol-based solution in the early stage of healing after EMR remains unclear. Uraoka et al. [12] 
compared glycerol and saline solution for EMR in patients with colorectal laterally spreading tumours. Glycerol provided a better resection rate but there was only a positive trend to parallel lower local recurrence rate (statistically not significant) [12]. Feitoza et al. [23] tested hydroxypropyl methylcellulose in experimental pigs. Hydroxypropyl methylcellulose was injected into the oesophageal submucosa (no subsequent EMRs were done). Histologic findings were fully normal only at $6 \%$ of the sites. Histology demonstrated negligible alterations in 33 of 36 (92\%) places, including the presence of a minimal amount of residual hydroxypropyl methylcellulose [23]. As no EMR was performed, this study could be compared only partly with our experiment. Nevertheless, deeper injection could administrate some hydroxypropyl methylcellulose into the muscular layer or even to the adventitia/serosa.

Mucosal wound healing is a complex process. The initial stage of healing within the first $24 \mathrm{~h}$ is characterised mostly by substantial infiltrate of neutrophils. By days 3-5, neutrophils have been largely replaced by monocytemacrophage lines and fibroblasts, and granulation tissue progressively invades the healing area. Migration and proliferation of both parenchymal and connective tissue cells have been augmented [24]. Adequate reconstitution requires the coordinated interaction of endothelial cells and fibroblasts during the proliferation phase of healing. Endothelial cells assure neoangiogenesis, fibroblasts fill the defect and provide extracellular matrix proteins, and myofibroblasts are believed to support the reconstitution of microvessels [25]. The extracellular matrix is constituted by collagen and elastic fibres, proteoglycans (heparan sulphates), adhesive glycoproteins (fibronectin) and integrins. By the end of the first week, there is continued collagen accumulation and fibroblast proliferation. The leukocyte infiltrate and increased vascularity are substantially diminished [24]. At this stage, collagen and elastic fibres are the most relevant markers of healing. In our study 1 week after EMR, we found a significantly higher content of both collagen and elastic fibres in healing lesions having used solution A (glycerol-based) for submucosal injection for EMR compared with solution B (containing hydroxypropyl methylcellulose). This exact assessment was made possible owing to objective image analysis using computer software. Such an evaluation would not be conceivable with the naked eye. Both EMR lesions were of the same size, made in the gastric body during the same session in all animals, and thus fully comparable.

Studies in healing of gastric ulcers showed that extracellular matrix components (procollagens, collagen type I, III and IV, laminin, fibronectin) play an important role in attachment, migration and repair of wounded cultured gastric epithelial cells [26], in experimental animals [27] and in healing of gastric ulcers in humans [28, 29].
The leukocyte compartment in the blood and gastric tissue at the site of treatment was determined by double colour immunophenotyping and flow cytometry at the time of the submucosal injection of particular solutions for EMR (either A or B) and 7 days later. The samples of gastric mucosa obtained by means of EMR and healing lesions collected at autopsy 7 days later were histologically different. While gastric samples from the beginning of the experiment mostly consisted of undamaged layer of mucosa containing only a few intraepithelial lymphocytes and a population of lamina propria lymphocytes with $\mathrm{TCR} \alpha \beta^{+}$T-cells and TCR $\gamma \delta^{+}$T cells possessing the CD ${ }^{+}$ and/or $\mathrm{CD}^{+}$surface phenotype and some NK cells [30], the healing gastric lesion 7 days after EMR was infiltrated by increased numbers of myelomonocytic cells in both samples, which corresponded to the healing process within the mucosal layer. The slightly increased relative numbers of $\mathrm{CD}^{+}{ }^{+}$single-positive T-cells at the site of EMR 7 days after the endoscopy may reflect the recruitment from circulation of helper/regulatory $\mathrm{T}$ lymphocytes with a possible role in regulating the healing process via the cytokine network. The accumulation of myelomonocytic cells within the damaged tissue is a typical example of monocyte and granulocyte recruitment during the inflammatory and healing process, where such cells play an important role in the tissue repair process [31]. In our setting, there was no significant difference in the proportion of $\mathrm{SWC}^{+}$leukocytes in the healing lesion after EMRs on day 7 between the use of solutions A and B for submucosal injection. However, the power of the performed test (0.198) was below the desired power of 0.800 . This could indicate that we were more likely not to detect a difference when one actually existed. This is why it is necessary to be cautions in overinterpreting the lack of difference found here. We hypothesise that the difference could be identified some time earlier. Lower proportions of B cells in the gastric samples (less than 5\% of lymphocytes when compared with the circulation where typically more than $10 \%$ of $\operatorname{sIgM}^{+}$lymphoid cells were present) is typical for lymphocyte subset composition of suspension isolated from nonlymphatic tissues.

One possible limitation of our current study is that it did not deal with the final outcome of EMR. Kamler et al. [32] performed circumferential oesophageal EMRs in experimental pigs. Saline solution was used for submucosal injection. Oesophageal strictures developed in three of eight animals over 3-5 weeks [32]. Thus we can speculate whether different solutions for submucosal injection would influence not only early healing but also final outcome of EMR. However, in the early stage of wound healing (within the first 14 days), presence of collagen (together with elastic fibres and granulous tissue) is not related to scar formation. At this stage, collagen and elastic fibres are 
the most relevant markers of healing. Last but not least, we do not think that blood supply would influence the rate of healing (i.e. content of collagen and elastic fibres). The porcine gastric fundus is larger compared to the human one, supplied mostly by the left gastric artery [33]. However, there is no difference in blood supply of the anterior and posterior walls of the porcine gastric body [34, 35], accounting for half of total gastric blood flow [36]. The fundus and gastric body can be easily recognised and distinguished at gastroscopy with a clear sharp borderline (mucosa of the gastric fundus is markedly darker). All EMRs in our study were placed in the central part of the gastric body.

In conclusion, both glycerol- and hydroxypropylmethylcellulose-based solutions provided optimal lifting of the mucosa before EMRs. The use of glycerol-based solution for submucosal injection was associated with more distinct signs of early healing in experimental pigs.

Acknowledgements The authors are grateful to Mrs. Sylva Cvejnová, Mrs. Ludmila Pavlatová, Mrs. Šárka Průchová and Mrs. Iveta Tóthová for their excellent technical assistance. The study was supported by research project MZO 00179906 from the Ministry of Health.

Open Access This article is distributed under the terms of the Creative Commons Attribution Noncommercial License which permits any noncommercial use, distribution, and reproduction in any medium, provided the original author(s) and source are credited.

\section{References}

1. Soetikno RM, Gotoda T, Nakanishi Y, Soehendra N (2003) Endoscopic mucosal resection. Gastrointest Endosc 57:567-579

2. Tada M, Murata M, Murakami F (1984) Development of strip-off biopsy (in Japanese with English abstract). Gastroenterol Endosc 26:833-839

3. Inoue H, Takeshita K, Hori H, Muraoka Y, Yoneshima H, Endo M (1993) Endoscopic mucosal resection with a cap-fitted panendoscope for esophagus, stomach, and colon mucosal lesions. Gastrointest Endosc 39:58-62

4. Tanabe S, Koizumi W, Kokutou M, Imaizumi H, Ishii K, Kida M, Yokoyama Y, Ohida M, Saigenji K, Shimao H, Mitomi H (1999) Usefulness of endoscopic aspiration mucosectomy as compared with strip biopsy for the treatment of gastric mucosal cancer. Gastrointest Endosc 50:819-822

5. Shim C-S (2001) Endoscopic mucosal resection: an overview of the value of different techniques. Endoscopy 33:271-275

6. Inoue H, Fukami N, Yoshida T, Kdo SE (2002) Endoscopic mucosal resection for esophageal and gastric cancers. J Gastroenterol Hepatol 17:382-388

7. Norton ID, Wang L, Levine SA, Burgart LJ, Hofmeister EK, Rumalla A, Gostout CJ, Petersen BT (2002) Efficacy of colonic submucosal saline solution injection for the reduction of iatrogenic thermal injury. Gastrointest Endosc 56:95-99

8. Yamamoto H, Koiwai H, Yube T, Isoda N, Sato Y, Sekine Y, Higashizawa T, Utsunomiya K, Ido K, Sugano K (1999) A successful single-step endoscopic resection of a 40 millimeter flat- elevated tumor in the rectum: endoscopic mucosal resection using sodium hyaluronate. Gastrointest Endosc 50:701-704

9. Yamamoto H, Kawata H, Sunada K, Satoh K, Kaneko Y, Ido K, Sugano K (2002) Success rate of curative endoscopic mucosal resection with circumferential mucosal incision assisted by submucosal injection of sodium hyaluronate. Gastrointest Endosc 56:507-512

10. Yamamoto H, Kawata H, Sunada K, Sasaki A, Nakazawa K, Miyata T, Sekine Y, Yano T, Satoh K, Ido K, Sugano K (2003) Successful en-bloc resection of large superficial tumors in the stomach and colon using sodium hyaluronate and small-calibertip transparent hood. Endoscopy 35:690-694

11. Fujishiro M, Yahagi N, Kashimura K, Mizushima Y, Oka M, Enomoto S, Kakushima N, Kobayashi K, Hashimoto T, Iguchi M, Shimizu Y, Ichinose M, Omata M (2004) Comparison of various submucosal injection solutions for maintaining mucosal elevation during endoscopic mucosal resection. Endoscopy 36:579-583

12. Uraoka T, Fujii T, Saito Y, Sumiyoshi T, Emura F, Bhandari P, Matsuda T, Fu KI, Saito D (2005) Effectiveness of glycerol as a submucosal injection for EMR. Gastrointest Endosc 61: 736-740

13. Fujishiro M, Yahagi N, Nakamura M, Kakushima N, Kodashima S, Ono S, Kobayashi K, Hashimoto T, Yamamichi N, Tateishi A, Shimizu Y, Oka M, Ogura K, Kawabe T, Ichinose M, Omata M (2006) Successful outcomes of a novel endoscopic treatment for GI tumors: endoscopic submucosal dissection with a mixture of high-molecular-weight hyaluronic acid, glycerin, and sugar. Gastrointest Endosc 63:243-249

14. Katsinelos P, Kountouras J, Paroutoglou G, Zavos C, Rizos C, Beltsis A (2006) Endoscopic mucosal resection of large sessile colorectal polyps with submucosal injection of hypertonic 50 percent dextrose-epinephrine solution. Dis Colon Rectum 49:1384-1392

15. Lee S-H, Park J-H, Hyun Park D, Chung IK, Kim HS, Park SH, Kim SJ, Cho HD (2006) Clinical efficacy of EMR with submucosal injection of a fibrinogen mixture: a prospective randomized trial. Gastrointest Endosc 64:691-696

16. Sato T (2006) A novel method of endoscopic mucosal resection assisted by submucosal injection of autologous blood (blood patch EMR). Dis Colon Rectum 49:1636-1641

17. Varadarajulu S, Tamhane A, Slaughter RL (2006) Evaluation of dextrose $50 \%$ as a medium for injection-assisted polypectomy. Endoscopy 38:907-912

18. Hurlstone DP, Fu KI, Brown SR, Thomson M, Atkinson R, Tiffin N, Cross SS (2008) EMR using dextrose solution versus sodium hyaluronate for colorectal Paris type I and 0-II lesions: a randomized endoscopist-blinded study. Endoscopy 40:110-114

19. Kararli TT (1995) Comparison of the gastrointestinal anatomy, physiology and biochemistry of humans and commonly used laboratory animals. Biopharm Drug Dispos 16:351-380

20. Fujishiro M, Yahagi N, Kashimura K, Matsuura T, Nakamura M, Kukushima N, Kodashima S, Ono S, Kobayashi K, Hashimoto T, Yamamichi N, Tateishi A, Shimizu Y, Oka M, Ichinose M, Omata M (2005) Tissue damage of different submucosal injection solutions for EMR. Gastrointest Endosc 62:933-942

21. Sinkora J, Rehakova Z, Sinkora M, Cukrowska B, TlaskalovaHogenova H, Bianchi AT, De Geus B (1998) Expression of CD2 on porcine B lymphocytes. Immunology 95:443-449

22. Explanatory Report on the European Convention for the Protection of Vertebrate Animals Used for Experimental and Other Scientific Purposes (1986) Council of Europe, Strasbourg

23. Feitoza AB, Gostout CJ, Burgart LJ, Burkert A, Herman LJ, Rajan E (2003) Hydroxypropyl methylcellulose: a better submucosal fluid cushion for endoscopic mucosal resection. Gastrointest Endosc 57:41-47 
24. Mitchell RN, Cotran RS (2003) Tissue repair: cell regeneration and fibrosis. In: Kumar V, Cotran RS, Robbins SL (eds) Robbins Basic Pathology, 7th edn. Saunders, Philadelphia, pp 61-78

25. Oberringer M, Meins C, Bubel M, Pohlemann T (2008) In vitro wounding: effects of hypoxia and transforming growth factor beta(1) on proliferation, migration and myofibroblastic differentiation in an endothelial cell-fibroblast co-culture model. J Mol Histol 39:37-47

26. Fujiwara Y, Arakawa T, Fukuda T, Higuchi K, Kobayashi K, Tarnawski A (1995) Role of extracellular matrix in attachment, migration, and repair of wounded rabbit cultured gastric cells. J Clin Gastroenterol 21(Suppl 1):S125-S130

27. Shahin M, Gillessen A, Pohle T, Weber C, Schuppan D, Herbst H, Domschke W (1997) Gastric ulcer healing in the rat: kinetics and localisation of de novo procollagen synthesis. Gut 41: 187-194

28. Gillessen A, Shahin M, Pohle T, Foerster E, Krieg TH, Domschke W (1995) Evidence of de novo collagen synthesis in healing human gastric ulcers. Scand J Gastroenterol 30:515-518

29. Gillessen A, Voss B, Rauterberg J, Domschke W (1993) Distribution of collagen types I, III, and IV in peptic ulcer and normal gastric mucosa in man. Scand J Gastroenterol 28:688-689

30. Nakagawa K, Higuchi K, Arakawa T, Kobayashi K, Kaneda K (2000) Phenotypical and morphological analyses of intraepithelial and lamina propria lymphocytes in normal and regenerating gastric mucosa of rats in comparison with those in intestinal mucosa. Arch Histol Cytol 63:159-167

31. Chamorro S, Revilla C, Alvarez B, Alonso F, Ezquerra A, Dominguez J (2005) Phenotypic and functional heterogeneity of porcine blood monocytes and its relation with maturation. Immunology 114:63-71

32. Kamler JP, Borsatto R, Binmoeller KF (2002) Circumferential endoscopic mucosal resection in the swine esophagus assisted by a cap attachment. Gastrointest Endosc 55:923-928

33. Arepally A, Barnett BP, Montgomery E, Patel TH (2007) Catheter-directed gastric artery chemical embolization for modulation of systemic ghrelin levels in a porcine model: initial experience. Radiology 244:138-143

34. Piasecki C, Wyatt C (1986) Patterns of blood supply to the gastric mucosa. A comparative study revealing an end-artery model. J Anat 149:31-39

35. Seto Y, Nakayama H, Ishigami H, Fujii S, Ueda E (1999) An experimental study of intramural blood supply network of the stomach wall. Hepato-Gastroenterology 46:2673-2676

36. Zamora CS, Reddy VK (1981) Regional blood flow to the stomach and small intestine in swine. Am J Vet Res 42: $1531-1533$ 